\title{
Spatial variation in community structure of a subtropical evergreen broad-leaved forest: Implications for sampling design
}

\author{
LIN DunMei ${ }^{1,2}$, LAI JiangShan $^{1}$, MI XiangCheng ${ }^{1}$, REN HaiBao $^{1} \&$ MA KePing $^{1 *}$ \\ ${ }^{1}$ State Key Laboratory of Vegetation and Environmental Change, Institute of Botany, Chinese Academy of Sciences, Beijing 100093, China; \\ ${ }^{2}$ Graduate University of Chinese Academy of Sciences, Beijing 100049, China
}

Received July 9, 2012; accepted September 24, 2012; published online December 24, 2012

\begin{abstract}
With the full survey data for a 24-ha subtropical evergreen broad-leaved forest dynamics plot, we evaluated spatial variation in forest structure characteristics (basal area and aboveground biomass), and calculated the minimal sample size and total sampling area necessary to estimate the forest structure characteristics within $20 \%( \pm 10 \%)$ of the observed values with $95 \%$ probability for particular quadrat sizes by using a computer program that is designed to simulate the sampling process by allowing different sized quadrats to be randomly located within the sampling region. We found that (1) based on the $60020 \mathrm{~m} \times 20 \mathrm{~m}$ subplots, basal area and aboveground biomass displayed a high degree of variation, with respective coefficients of variation of $27 \%$ and $31 \%$; (2) based on the computer simulation analysis, the variability of basal area and aboveground biomass decreased with increasing quadrat size. The number of quadrats required to achieve the specified degree of precision dropped sharply with the increase of quadrat size. However, the total sampling area increased with increasing quadrat size, suggesting that using several small quadrats across the sampling area is more efficient than using fewer larger quadrats. Results of this study are valuable for evaluating the reliability of previous research and may assist researchers in designing effective sampling strategies for future field surveys, particularly in subtropical evergreen broad-leaved forests in China.
\end{abstract}

spatial variation, basal area, aboveground biomass, quadrat size, sample size

Citation: Lin D M, Lai J S, Mi X C, et al. Spatial variation in community structure of a subtropical evergreen broad-leaved forest: Implications for sampling design. Chin Sci Bull, 2013, 58: 1181-1186, doi: 10.1007/s11434-012-5586-0

As one of the most important ecosystems on the earth, forest not only provides human beings with food, medicine and many kinds of raw materials, but also plays an important role in climate regulation, water conservation and environment maintenance, etc. [1]. Just because of its vital role in the development of human society, forest gains great concern worldwide and becomes an important research object of science. With the intensification of species loss, global climate change and other environmental issues, forest species coexistence mechanism and the role of forest ecosystems in global carbon cycles become the central topic of current ecological studies [2,3]. In recent years, ecologists have presented many scientific hypothesis based on extensive observational and experimental studies. For example, it was found through long-term monitoring that the biomass of

*Corresponding author (email: kpma@ibcas.ac.cn) old-growth tropical forest had significantly risen in the past few decades [4,5]. Therefore, some scholars proposed a hypothesis that primary forests or old-growth forests might still be carbon sinks [5], which challenged the traditional view that the community structure and functions of mature forest tend to dynamic equilibrium [6]. Due to the lack of historical data on forest disturbance, these conclusions have caused bigger controversy [7]. As a result, the future development trend is to carry out further studies to verify the hypothesis or propose new hypotheses.

Sampling survey is an important approach for forest ecological studies, and lots of experience and theories are obtained and verified based on the analysis of quadrat survey data [8]. Due to the influence of environment, community process, and natural or human disturbance, the community structure tends to have strong spatial variability. For example, influenced by the topography, soil nutrient, light 
condition, disturbance and other factors, the spatial distribution of the aboveground biomass at Barro Colorado Island, Panama showed significant variability $[9,10]$. Spatial variability of community structure brings large difficulties to community survey. Whether community survey can accurately reflect the true character of the community structure depends on whether the chosen sampling area and the number of quadrats are representative. In actual survey, people tend to choose well-grown or undisturbed forest as the survey object, which may cause a substantial deviation of results [11]. Ideally, the larger the sampling area is and/or the more the number of quadrats is, the accurately the true character of community can be reflected. However, subject to constraints on funds and survey time, the ideal state cannot be achieved. Therefore, it is necessary to design appropriate quadrat size and sample size in order to obtain the most representative community survey data on the basis of minimum funds and time [12]. As to sampling design for community survey, many studies have been carried out in tropical and temperate forests [8,9,13-17]. However, although the subtropical evergreen broad-leaved forests are widely distributed in China [18], and the domestic scholars have conducted lots of studies on the community structure of subtropical evergreen broad-leaved forests in the past several decades (Table S1), few of them touched upon the sampling design based on comprehensive survey data. Most previous studies were based on a fixed small plot or small number of quadrats (Table S1). For example, Yang et al. [19] estimated that the biomass of a 52-years-old Schima superba-Castanopsis carlesii forest in Tiantongshan, Zhejiang Province was $225.3 \pm 30.1 \mathrm{Mg} / \mathrm{ha}$ based on 5 quadrats with a size of $20 \mathrm{~m} \times 20 \mathrm{~m}$. How about its reliability? Whether or not the survey results based on the 5 quadrats sized $20 \mathrm{~m} \times$ $20 \mathrm{~m}$ could truly reflect the community biomass? So far, there has not been a comparatively reliable evaluation basis.

The Gutianshan 24-ha forest dynamic plot of typical subtropical evergreen broad-leaved forest was established in 2005 [20]. All trees $\geqslant 1 \mathrm{~cm}$ in diameter at breast height were tagged, mapped, measured and identified to species [20]. Taking the basal area and aboveground biomass as the study objects, this study randomly samples different sized quadrats by computer simulation, and analyzes the spatial variability of basal area and aboveground biomass. We addressed two specific issues: (1) Assessing the spatial variability of community structure (basal area and aboveground biomass);

(2) Calculating the minimum number of quadrats required for estimations of basal area and aboveground biomass to meet a specified accuracy when random sampling with different sized quadrats.

\section{Methods}

\subsection{Study site and data collection}

This study was carried out in Gutianshan National Nature
Reserve (GNNR) located in Kaihua County, Zhejiang Province, China $\left(29^{\circ} 10^{\prime} 19.4^{\prime \prime}-29^{\circ} 17^{\prime} 41.4^{\prime \prime} \mathrm{N}, 118^{\circ} 03^{\prime} 49.7^{\prime \prime}-\right.$ $\left.118^{\circ} 11^{\prime} 12.2^{\prime \prime} \mathrm{E}\right)$. Total area of GNNR is about 8,000 ha. This place is characterized by subtropical monsoon climate, with a mean annual temperature of $15.3^{\circ} \mathrm{C}$ and a mean annual precipitation of $1964 \mathrm{~mm}$ [21]. The dominant soil can be classified into red, red-yellow, yellow-red and marsh soils, and soil pH ranges from 5.5-6.5 [21]. A total of 1426 seed-plant species of 648 genera and 149 families have been recorded as occurring naturally in GNNR [22]. The predominant vegetation type of GNNR is subtropical evergreen broad-leaved forest dominated by Castanopsis eyrei, Schima superba and Cyclobalanopsis glauca [21].

In 2005, a 24-ha permanent plot was established in the core area of GNNR (Figure 1) as part of the Chinese Forest Biodiversity Monitoring Network. The plot was divided into 600 subplots $(20 \mathrm{~m} \times 20 \mathrm{~m})$ marked with 651 cement pegs. All trees with diameter at breast height $(\mathrm{dbh}) \geqslant 1 \mathrm{~cm}$ were measured, tagged, mapped, and identified to species. We encountered 159 species belonging to 103 genera and 49 families in the plot [20].

\subsection{Study objects selection}

We selected the basal area and aboveground biomass as the objects of simulated sampling. Basal area is the cross-sectional area at breast height $(1.3 \mathrm{~m})$, and aboveground biomass is estimated using published allometric equations. The 11 species-specific and 1 genera-specific allometric equations were available for the common species of our study plot (Table S2). Where multiple equations were available for the same species, we used the one developed for the closest geographic location [23]. For those species that did not have species-specific or genera-specific allometric equation, the aboveground biomass was calculated by using the generalized equation of Zhang et al. [24] for subtropical forests in Zhejiang Province. Tree height was estimated via 47 species-specific and one generalized regression models developed from a sample of 1066 trees collected in our study plot (Table S3).

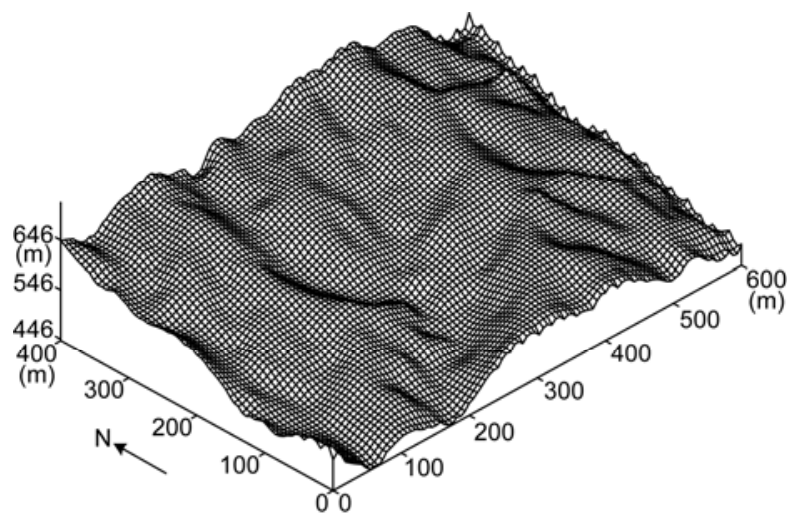

Figure 1 Topography of the 24-ha Gutianshan plot. 


\subsection{Simulated sampling}

To ensure the simulation results include all possible variations, we use the following sampling method: Randomly select a point in the 24-ha plot and expand outward to specific side length (quadrat) centered on this point. Then calculate the basal area and aboveground biomass of each tree in the quadrat, and add together to calculate the total basal area and total aboveground biomass of the quadrat respectively. Finally, convert these values into the corresponding values per unit area. Repeat the steps listed above 10000 times for different sized quadrats. Side lengths of quadrats for simulated sampling were set as $10,20,30,40,50,80$, 100,150 and $200 \mathrm{~m}$, i.e. the minimum quadrat area is 0.01 ha and the maximum quadrat area is 4 ha. During simulated sampling, a buffer was supposed to be set at the edge of 24-ha plot according to the side length of quadrat to prevent quadrats from dropping out of the study plot. For instance, when the side length of quadrat is $10 \mathrm{~m}$, the buffer width was set as $5 \mathrm{~m}$.

\subsection{Data analysis}

The observed value of basal area and aboveground biomass were obtained through dividing the total basal area and aboveground biomass of the entire plot by the total area of the study plot (24 ha). We divided the 24-ha plot into 600 $20 \mathrm{~m} \times 20 \mathrm{~m}$ subplot to assess the spatial variability of basal area and aboveground biomass, and used coefficients of variation $(\mathrm{CV})$ to represent them.

Basic statistics (mean, standard deviation, maximum, minimum and CV) were calculated for all sampling distributions for every sized quadrat produced by random sampling as described above. The relationship between $\mathrm{CV}$ and quadrat area was analyzed using simple linear regression.

Based on the data set obtained through the 10000 times random sampling, we calculated the minimum number of quadrats required to ensure there was $95 \%$ probability for the estimated values to within $20 \%( \pm 10 \%)$ of the observed values. The formula is as follows [8]:

$$
n=\left[\frac{s t_{0.05}}{d}\right]^{2},
$$

where $n$ is the minimum number of quadrats; $s$ is standard deviation of the sampling distributions; $t$ is the Student's $t$-statistic (set to 1.96 , without regard to its changes); $d$ is the observed value $\times 10 \%$. Besides, we calculated the error range where the estimated value had $95 \%$ probability to fall when randomly sampling 2, 4 and 6 quadrats sized $20 \mathrm{~m} \times$ $20 \mathrm{~m}$ and $30 \mathrm{~m} \times 30 \mathrm{~m}$ respectively. Simulated sampling procedures and subsequent analysis were performed using the R project software version 2.12.1 [26]. Simulated sampling routine can be found in Supporting Information (Text S1).

\section{Result}

\subsection{Spatial variation of basal area and aboveground biomass}

As shown in Figure 2, based on the $60020 \mathrm{~m} \times 20 \mathrm{~m}$ subplots, the basal area and aboveground biomass showed significant spatial variability. The maximum of basal area and aboveground biomass are 5.9 times and 6.5 times of the minimum respectively. The variability of aboveground biomass is greater than that of the basal area (Table 1).

Results of simulated sampling also showed that the basal area and aboveground biomass have significant variability (Figure 3). With the increase of quadrat area, their variability decreases gradually (Figure 3 ). The negative correlation between $\mathrm{CV}$ and quadrat area also indicates that their variability is relatively low when large quadrats are used for sampling (Figure 4). In this study, when the quadrat size is set as $10 \mathrm{~m} \times 10 \mathrm{~m}$, their variability is maximum, and the $\mathrm{CV}$ of basal area and aboveground biomass is $47.2 \%$ and $52.7 \%$ respectively. Although sampling with comparatively larger quadrats significantly decrease the variability (Figure 3), their variability still cannot be ignored. For example, when the quadrat area is set as 1 ha, the estimated value of basal
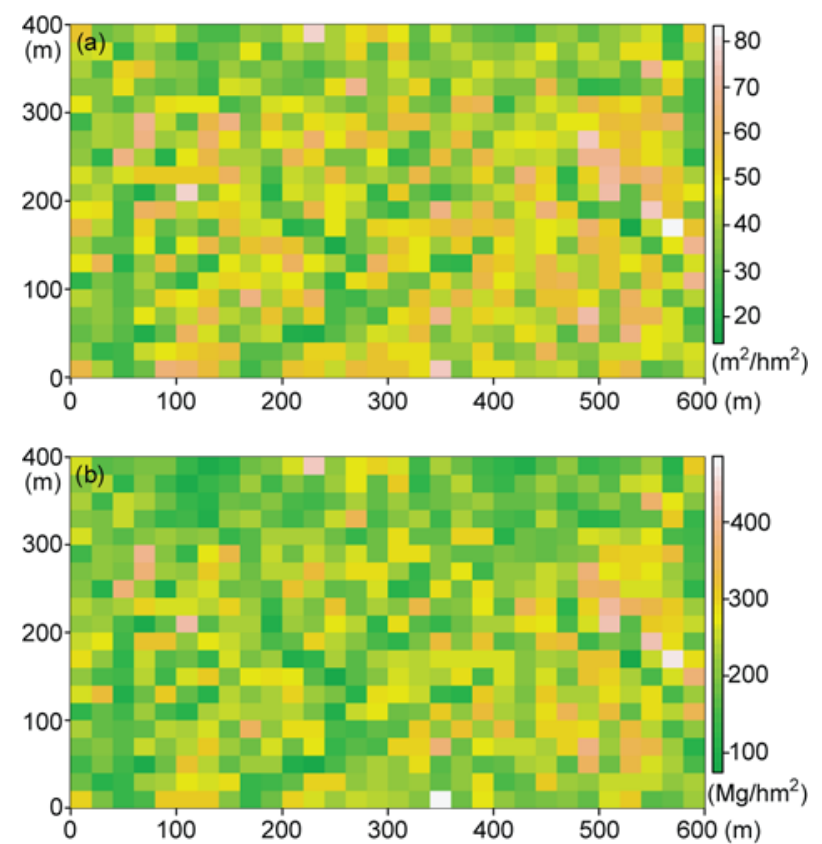

Figure 2 Spatial distribution of basal area (a) and aboveground biomass (b) based on the $60020 \mathrm{~m} \times 20 \mathrm{~m}$ subplots.

Table 1 Variability of basal area and aboveground biomass based on the $60020 \mathrm{~m} \times 20 \mathrm{~m}$ subplots

\begin{tabular}{ccccc}
\hline Study object & Mean & Maximum & Minimum & $\mathrm{CV}(\%)$ \\
\hline $\begin{array}{c}\text { Basal area }\left(\mathrm{m}^{2} / \mathrm{ha}\right) \\
\begin{array}{c}\text { Aboveground biomass } \\
(\mathrm{Mg} / \mathrm{ha})\end{array}\end{array}$ & 43.47 & 83.38 & 14.25 & 27 \\
\hline
\end{tabular}



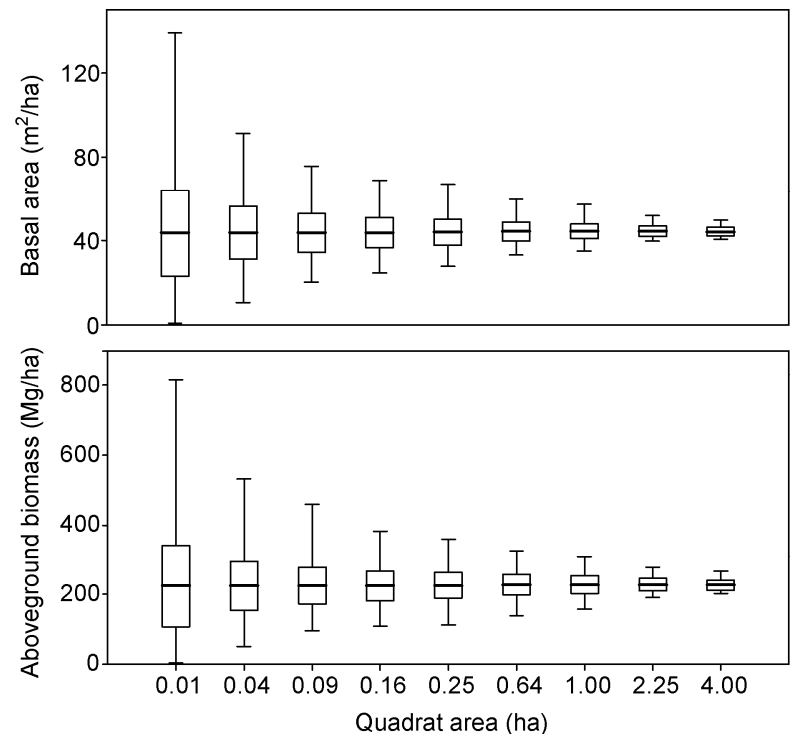

Figure 3 Variability of basal area and aboveground biomass at different quadrat area based on 10000 times random sampling. Broad line indicates the mean value; the box means \pm standard deviation and whiskers mean minimum and maximum values.

area range from 34.8 to $57.1 \mathrm{~m}^{2} / \mathrm{ha}$, and the aboveground biomass range from 156.3 to $307.8 \mathrm{Mg} / \mathrm{ha}$. Therefore, a fixed survey quadrat of 1 ha cannot accurately represent the true character of the surveyed community all the time.

\subsection{Estimate of the minimum sample size}

According to formula (1), we estimated the minimum number of quadrats required to ensure there was $95 \%$ probability for

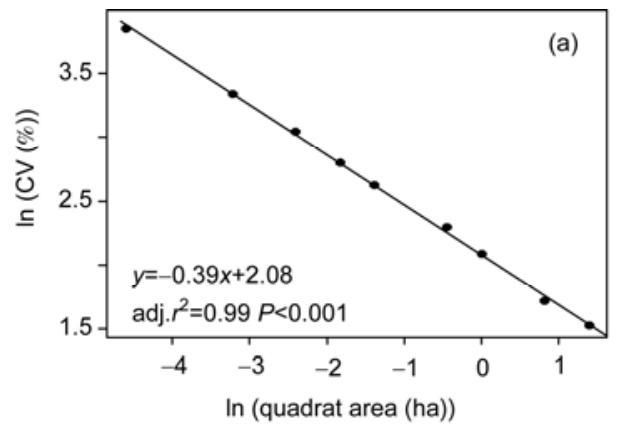

the estimated values to within $20 \%( \pm 10 \%)$ of the observed values (Table 2), and meanwhile calculated the error range where the estimated value had $95 \%$ probability to fall when randomly sampling 2, 4 and 6 quadrats sized $20 \mathrm{~m} \times 20 \mathrm{~m}$ and $30 \mathrm{~m} \times 30 \mathrm{~m}$ (Table 3). As shown in Table 2, with continuous increase in the quadrat area, the number of quadrats required decreases gradually while the necessary total sampling area tends to increase. For example, when sampling with quadrats sized $10 \mathrm{~m} \times 10 \mathrm{~m}$ to estimate aboveground biomass, the number of quadrats required is 101 and total sampling area is 1.01 ha. When sampling with quadrats sized $100 \mathrm{~m} \times 100 \mathrm{~m}$, the number of quadrats required is only 4 , but total sample area reaches 4 ha (Table 2). When only one quadrat is set, in order to meet the same accuracy, the quadrat area should be 2.25 ha in terms of the basal area, and be 4 ha in terms of aboveground biomass. Therefore, sampling with small quadrats, the spatial variability is greater than that when sampling with large quadrats (Figure 3 ), and the number of quadrats required is more than that sampling with large quadrats. However, from the perspective of total sampling area, sampling with certain number of small quadrats can achieve higher efficiency (Table 2). As shown in Table 3, when we randomly sample 2, 4 and 6 quadrats with quadrats sized $20 \mathrm{~m} \times 20 \mathrm{~m}$ and $30 \mathrm{~m} \times 30 \mathrm{~m}$, the estimated values may considerably deviate from the observed values. For instance, when 2 quadrats sized 20 $\mathrm{m} \times 20 \mathrm{~m}$ are used to estimate aboveground biomass, the deviation may reach $\pm 43.7 \%$, i.e. the estimated value of biomass may range from 125.57 to $320.49 \mathrm{Mg} / \mathrm{ha}$, and even the deviation may reach $\pm 25.2 \%$ when 6 quadrats are randomly sampled (Table 3).

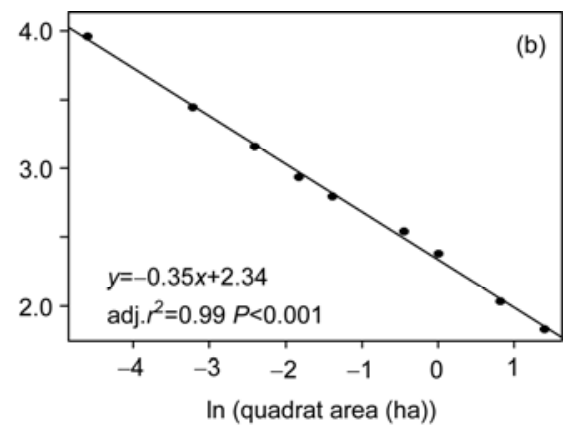

Figure 4 The relationships between quadrat area and coefficients of variation (CV) of basal area (a) and aboveground biomass (b).

Table 2 Required number of quadrats and total sampling area for estimation of basal area and aboveground biomass to within $20 \%$ ( $\pm 10 \%$ ) of the observed value with $95 \%$ confidence for various quadrat sizes

\begin{tabular}{|c|c|c|c|c|c|c|c|c|c|c|}
\hline \multicolumn{2}{|c|}{ Quadrat area (ha) } & 0.01 & 0.04 & 0.09 & 0.16 & 0.25 & 0.64 & 1 & 2.25 & 4 \\
\hline \multirow{2}{*}{ Basal area } & No. of quadrats & 86 & 31 & 17 & 11 & 7 & 4 & 3 & 1 & 1 \\
\hline & Total area (ha) & 0.86 & 1.24 & 1.53 & 1.76 & 1.75 & 2.56 & 3 & 2.25 & 4 \\
\hline \multirow{2}{*}{ Aboveground biomass } & No. of quadrats & 101 & 36 & 20 & 13 & 10 & 6 & 4 & 2 & 1 \\
\hline & Total area (ha) & 1.01 & 1.44 & 1.8 & 2.08 & 2.5 & 3.84 & 4 & 4.5 & 4 \\
\hline
\end{tabular}


Table 3 The error range where the estimated value had $95 \%$ probability to fall when randomly sample 2, 4 and 6 quadrats sized $20 \mathrm{~m} \times 20 \mathrm{~m}$ and $30 \mathrm{~m} \times 30 \mathrm{~m}$

\begin{tabular}{lcccc}
\hline \multirow{2}{*}{ Study object } & $\begin{array}{c}\text { Quadrat area } \\
\text { (ha) }\end{array}$ & \multicolumn{3}{c}{ No. of quadrats (\%) } \\
\cline { 3 - 5 } & 0.04 & \pm 39.4 & \pm 27.9 & \pm 22.8 \\
\hline \multirow{2}{*}{ Basal area } & 0.09 & \pm 29.3 & \pm 20.7 & \pm 16.9 \\
& 0.04 & \pm 43.7 & \pm 30.9 & \pm 25.2 \\
Aboveground biomass & 0.09 & \pm 32.9 & \pm 23.2 & \pm 19.0 \\
\hline
\end{tabular}

\section{Discussion}

This study analyzed the spatial variability of community structure (basal area and aboveground biomass) in a typical subtropical broad-leaved evergreen forest, and estimated the minimum number of quadrats required for estimation of basal area and aboveground biomass to meet a specified accuracy when random sampling with different sized quadrats. We found that the community structure has great spatial variability (Table 1, Figure 2). The variability of random sampling results were negatively correlated with quadrat area (Figures 3,4). All of these results are consistent with the studies conducted in tropical and temperate regions $[9,13,16]$. Although people have realized the variability of community structure and the importance of sampling design [27,28], these issues had been ignored. In the past, many studies only chose a few quadrats with small size or one fixed plot with larger but not big enough plot (such as $1 \mathrm{ha}$ ) (Table S1). Our findings suggest that taking full consideration of spatial variability of community structure during the survey, and sampling with higher number of small quadrats will often achieve a higher efficiency (Table 2).

Of course, this study also has some limitations. First, the simulated sampling in this study was conducted in only one place, i.e. a subtropical evergreen broad-leaved forest covering an area of 24 ha. However, the spatial variability of community structure is jointly caused by environment, community process, natural or human disturbance and other factors. Different climate types, different terrain conditions and different degrees of disturbance all can result in differences in community structure [29-31]. As a result, corresponding research carried out in different places can further improve the generalization of the results. Second, both of basal area and aboveground biomass are static parameters of community structure, but the dynamic parameters, such as growth, death and recruitment, are not involved in this study. Monitoring these dynamic parameters is an important approach to study the species coexistence mechanism and the response of forest ecosystems to climate change. Some researchers suggest that compared with static parameters of community structure, the dynamic parameters often shown greater variability $[8,9]$. Biodiversity monitoring network in
China continues to expand. Currently, nearly 20 forest dynamic plots of 5-25 ha have been established in different places in China, and each of them will be resurveyed every 5 years [32]. Undoubtedly, these survey results will provide the research related to sampling design with data support in a favorable manner.

We gratefully acknowledge the field workers for their contributions to the establishment and census of the 24-ha permanent forest plot. This work was supported by Key Innovation Project of Chinese Academy of Sciences $(K Z C X 2-Y W-430)$ and the Strategic Priority Research Program of Chinese Academy of Sciences (XDA05050204).

1 Bonan G B. Forests and climate change: Forcings, feedbacks, and the climate benefits of forests. Science, 2008, 320: 1444-1449

2 Wright S J. Plant diversity in tropical forests: a review of mechanisms of species coexistence. Oecologia, 2002, 130: 1-14

3 Malhi Y, Meir P, Brown S. Forest, carbon and global climate. Phil Trans R Soc Lond A, 2002, 360: 1567-1591

4 Baker T R, Phillips O L, Malhi Y, et al. Increasing biomass in Amazonian forest plots. Phil Trans R Soc Lond B Biol Sci, 2004, 359: 353-365

5 Lewis S L, Lopez-Gonzalez G, Sonke B, et al. Increasing carbon storage in intact African tropical forests. Nature, 2009, 457: 10031006

6 Odum E P. The strategy of ecosystem development. Science, 1969, 164: $262-270$

7 Wright S J. Tropical forests in a changing environment. Trends Ecol Evol, 2005, 20: 553-560

8 Wagner F, Rutishauser E, Blanc L, et al. Effects of plot size and census interval on descriptors of forest structure. Biotropica, 2010, 42: 664-671

9 Chave J, Condit R, Lao S, et al. Spatial and temporal variation of biomass in a tropical forest: Results from a large census plot in Panama. J Ecol, 2003, 91: 240-252

10 Mascaro J, Asner G P, Muller-Landau H C, et al. Controls over aboveground forest biomass density on Barro Colorado Island, Panama. Biogeosciences, 2011, 8: 1615-1629

11 Chave J, Condit R, Aguilar S, et al. Error propagation and scaling for tropical forest biomass estimates. Philos Trans R Soc Lond B Biol Sci, 2004, 359: 409-420

12 Evans T D, Viengkham O V. Inventory time-cost and statistical power: A case study of a Lao rattan. For Ecol Manage, 2001, 150: 313-322

13 Keller M, Palace M, Hurtt G. Biomass estimation in the Tapajos National Forest, Brazil: Examination of sampling and allometric uncertainties. For Ecol Manage, 2001, 154: 371-382

14 Pyle E H, Santoni G W, Nascimento H E M, et al. Dynamics of carbon, biomass, and structure in two Amazonian forests. J Geophys Res, 113, G00B08, doi:10.1029/2007JG000592

15 Laumonier Y, Edin A, Kanninen M, et al. Landscape-scale variation in the structure and biomass of the hill dipterocarp forest of Sumatra: Implications for carbon stock assessments. For Ecol Manage, 2010, 259: 505-513

16 Kral K, Janik D, Vrska T, et al. Local variability of stand structural features in beech dominated natural forests of Central Europe: Implications for sampling. For Ecol and Manage, 2010, 260: 2196-2203

17 Bradford J B, Weishampel P, Smith M, et al. Carbon pools and fluxes in small temperate forest landscapes: Variability and implications for sampling design. For Ecol Manage, 2010, 259: 1245-1254

18 Wang X H, Kent M, Fang X F. Evergreen broad-leaved forest in Eastern China: Its ecology and conservation and the importance of resprouting in forest restoration. For Ecol Manage, 2007, 245: 76-87

19 Yang T H, Song K, Da L J, et al. The biomass and aboveground net primary productivity of Schima superb-Castanopsis carlesii forests in east China. Sci China Life Sci, 2010, 53: 811-821 
20 Chen B, Mi X C, Fang T, et al. Gutianshan Forest Dynamic Plot: Tree Species and Their Distribution Pattern. Beijing: China Forestry Publishing House, 2009

$21 \mathrm{Hu}$ Z H, Yu M J, Ding B Y, et al. Types of evergreen broadleaved forest and the species diversity in Gutian Moutain Nature Reserve (in Chinese). Chin J Appl Environ Bio, 2003, 9: 341-345

22 Lou L H, Jin S H. Spermatophyta flora of Gutianshan Nature Reserve in Zhejiang (in Chinese). J Beijing Forest Univ, 2000, 22: 33-39

23 Brown S. Measuring carbon in forests: current status and future challenges. Environ Pollut, 2002, 116: 363-372

24 Zhang J, Chang J, Ge Y, et al. Carbon storage by ecological service forests in Zhejiang Province, subtropical China. For Ecol Manage, 2007, 245: 64-75

25 Li C X, Jiang L N, Shao Y, et al. Biostatistics (in Chinese). 3rd ed. Beijing: Science Press, 2005

26 R Development Core Team. R: A language and environment for statistical computing. R Foundation for Statistical Computing, 2010,
Vienna, Austria. ISBN 3-900051-07-0, URL http://www.R-project.org/

27 He M G. Pilot study on the plot size of subtropical mountain evergreen broad-leaved and conifer forest (in Chinese). Chin J Plant Ecol, 1964, 2: 118-127

28 Song Y C, Zhang S, Shi J L. Some problems in sampling of mountain secondary shrub and young forests (in Chinese). Chin J Plant Ecol, 1965, 3: 247-263

29 DeWalt S J. Structure and biomass of four lowland neotropical forests. Biotropica, 2004, 36: 7-19

30 Stegen J C, Swenson N G, Enquist B J, et al. Variation in aboveground forest biomass across broad climatic gradients. Global Ecol Biogeogr, 2011, 20: 744-754

31 McEwan R W, Lin Y, Sun I, et al. Topographic and biotic regulation of aboveground carbon storage in subtropical broad-leaved forests of Taiwan. For Ecol Manage, 2011, 262: 1817-1825

32 Ma K P. Assessing progress of biodiversity conservation with monitoring approach (in Chinese). Biodiver Sci, 2011, 19: 125-126

Open Access This article is distributed under the terms of the Creative Commons Attribution License which permits any use, distribution, and reproduction in any medium, provided the original author(s) and source are credited.

\section{Supporting Information}

Table S1 The sampling designs of previous studies conducted in subtropical evergreen broad-leaved forests in China

Table S2 Allometric equations used in this study

Table S3 Tree height-DBH regression models used in this study

Text S1 R routine for simulated sampling

The supporting information is available online at csb.scichina.com and www.springerlink.com. The supporting materials are published as submitted, without typesetting or editing. The responsibility for scientific accuracy and content remains entirely with the authors. 